\title{
The predictive value of two on-site selection methods of undergraduate nursing students: A cohort study
}

\author{
Kirsi Talman*1,2, Maija Hupli ${ }^{1}$, Pauli Puukka ${ }^{3}$, Helena Leino-Kilpi ${ }^{1,4}$, Elina Haavisto ${ }^{1,2}$ \\ ${ }^{1}$ Department of Nursing Science, University of Turku, Turku, Finland \\ ${ }^{2}$ Clinical nursing and Emergency Care, Metropolia University of Applied Sciences, Helsinki, Finland \\ ${ }^{3}$ National Institute for Health and Welfare, Turku, Finland \\ ${ }^{4}$ Turku University Hospital, Turku, Finland
}

Received: November 11, 2017

DOI: $10.5430 /$ jnep.v8n7p12
Accepted: January 11, $2018 \quad$ Online Published: January 29, 2018

URL: https://doi.org/10.5430/jnep.v8n7p12

\begin{abstract}
Nursing programs aim to select students who will succeed in theoretical studies and in clinical practice, and who are suitable for the profession. Recent literature has suggested an assessment of cognitive and non-cognitive skills in nursing student selection. The aim of this study is to compare the predictive value of two on-site selection methods used in nursing student selection, namely, psychological aptitude tests and literature-based exams. A cohort study was conducted. Students admitted to four undergraduate Bachelor of Science nursing programs at one Finnish nursing school between 2002 and $2004(\mathrm{~N}=626)$ were allocated into two cohorts based on the on-site selection method. Follow-up data was collected at two measurement points (May 2004-May 2009). The multimethod data collection included the use of admission archives (entrance exam scores), study records (study success) and a structured self-report questionnaire (knowledge and skills). Statistical data analysis was undertaken. According to the results, the two on-site selection methods produced very similar results regarding their predictive value. Both of the on-site selection methods predicted knowledge and skills, and study success of nursing students to some extent, but only explained a small proportion of variance. To conclude, neither of the two on-site selection methods should be used alone when predicting knowledge and skills or study success of nursing students. Further longitudinal research is needed to investigate the predictive value of various on-site selection methods.
\end{abstract}

Key Words: Students, Nursing, Student selection, Student admission, Person specification, Psychological aptitude test, Literature-based exam, Cohort study

\section{INTRODUCTION}

\subsection{The significance and current state of nursing student selections}

Nursing student selection processes have a huge impact on numerous higher education institutions and applicants seeking a study place in nursing education each year. It is reported that, globally, there are approximately 35 million nurses and midwives working within healthcare, ${ }^{[1,2]}$ giving an estimation of the scale of the student selection processes undertaken within nursing education. Nursing student selection processes have recently come under scrutiny due to international concerns of turnover rates in the field, ${ }^{[3,4]}$ increased student attrition rates, and concerns over a lack of compassion in the workplace. ${ }^{[3,5]}$ It is recognised that on-site student selection methods provide opportunities to evaluate person-centred skills ${ }^{[3]}$ in a way that "puts people

*Correspondence: Kirsi Talman; Email: kirsi.talman@metropolia.fi; Address: Clinical Nursing and Emergency Care, Metropolia University of Applied Sciences, PB 4000, 00079 Metropolia, Finland. 
first". [1] Furthermore, on-site selection methods most often include the assessment of learning/cognitive skills and non-cognitive skills. ${ }^{[6,7]}$ Assessment of learning/cognitive skills include, for example, testing of literacy, numeracy and problem-solving skills. ${ }^{\left[{ }^{8-12]}\right.}$ Recent literature also demonstrates the desirability to assess non-cognitive skills (also referred to as person specification, non-cognitive qualities or personal attributes) in the nursing student selection. ${ }^{[13,14]}$ It is recognised that the demands of the nursing profession such as personality, ${ }^{[3]}$ professional conduct, ${ }^{[15]}$ patient safety and quality of care ${ }^{[3,6]}$ should also guide the student selection. However, there is lack of evidence supporting the currently used on-site selection methods in nursing education. ${ }^{[12,16]}$ Further research is needed with cohorts to confirm the use of person specification ${ }^{[13]}$ and its predictability of study success.

In Finland, nursing education has a long history of using person specification in student selection processes, which were dominated by psychological aptitude tests, executed by psychologists, from the 1940 s to the year 2000. ${ }^{[16]}$ However, since the beginning of the new millennium, psychological aptitude tests have been considered financially burdening $^{[17]}$ and have been criticised of mainly de-selecting candidates. ${ }^{[18]}$ Furthermore, there has been very little evidence to support the predictive value of the psychological aptitude tests in the student selection of healthcare-related professions. ${ }^{[18]}$ Therefore, we wanted to evaluate the predictive value of the psychological aptitude tests, doing so in comparison to another on-site selection method. Literature-based examination was chosen to represent one of the simplest and most cost-effective on-site selection methods. We recognised that investigating the predictive value of the selection methods could have an important economic impact within the nursing field. Even though there is very little data gathered in Finland regarding the student selection costs, low predictive value or lack of significance are strong indicators of a method that is not cost-effective, and these indicators should therefore be of interest to the government and nursing school administration. There was also a need for evidence-based development of nursing student selections due to social and political reasons. Thus, the aim of this study was to compare the predictive value of two on-site selection methods used in nursing student selection, namely, psychological aptitude test and literature-based exam.

\subsection{Relevant literature on the on-site nursing student se- lection methods}

The on-site nursing student selection methods reported within the last 20 years include the use of selection interviews, ${ }^{[12,19]}$ Multiple Mini Interviews (MMIs), ${ }^{[7,20]}$ admis- sion essays, ${ }^{[21]}$ nationwide entry exams, ${ }^{[9,10]}$ standardised tests, ${ }^{[8,11,22]}$ and emotional intelligence tests. ${ }^{[3,23,24]}$

Individual and group interviews are widely used, for example, in the United Kingdom, because of the requirement from the Nursing and the Midwifery Council for face-to-face contact with nursing applicants. ${ }^{[12,15]}$ In a study by Ehrenfeld and Tabak, ${ }^{[19]}$ individual interviews were more often associated with reduced attrition compared to group interviews, past performance and psychometric testing. However, the attrition rate remained high $(30 \%)$ even with the use of individual interviews. Furthermore, interviewing methods were reported to have somewhat low predictive value for attrition, and concerns were raised regarding the objectivity of the interviewing as a method, ${ }^{[19]}$ therefore undermining to support for using interviews as a selection tool. ${ }^{[16]}$ In a study by MacDuff et al., ${ }^{[12]}$ lecturers, clinical staff and students gave their perspectives on interviewing processes. They concluded that students had very mixed opinions on interview processes, and staff reported mixed opinions of the validity and reliability of interview processes. Staff aimed to achieve holistic assessments in interview processes, taking into account a wide range of important candidate attributes, such as interpersonal skills, team working, confidence, problem solving, aptitude for caring, motivations and commitment. ${ }^{[12]}$

MMIs have been used as the on-site selection method in which both cognitive and non-cognitive attributes are most often assessed in nursing student selection. ${ }^{[7,20]}$ The assessment of non-cognitive attributes has included attributes such as empathy, ethical insights, initiative, teamwork, ${ }^{[7]}$ integrity, interpersonal skills and compassion. ${ }^{[20]}$ In a study by Gale et al., ${ }^{[7]}$ MMIs, in conjunction with numeracy and literacy scores, seemed to significantly predict academic success (assessment marks for modules in years 1, 2 and 3). Literacy marks only weakly predicted academic success. ${ }^{[7]}$

Admission essays have been used to support admission decisions in nursing education. Sadler et al., ${ }^{[21]}$ used admission essays to find out what the candidates knew of the nursing profession and why they were interested in nursing. The group essay scores were statistically different between the program completers and non-completers. The program completers' essays also portrayed internalisation of the role of a nurse, whereas non-completers described nursing as being external to themselves. ${ }^{[21]}$

A nationwide admission test is used to select nursing students among others in the higher education admission process in Italy. The test includes assessment of cognitive skills, including logic and general education, mathematics and physics, biology and chemistry. ${ }^{[9,10]}$ In a study by Dante et al., ${ }^{[9]}$ national admission test scores were associated with academic 
success. The chances of students with good entry exam scores to graduate within three years were four times as high as those with lower scores. However, in a study by Lancia et al., ${ }^{[10]}$ admission test scores did not show a positive correlation with final degree grades or GPA of exam scores.

Standardised tests, such as the American College Test (ACT), the Health Education Systems, Inc. exam (HESI), the National League for Nursing (NLN) Pre-Admission Exam and the Test of Essential Academic Skills (TEAS), have been found to be predictive of academic performance in nursing studies. The ACT, NLN and SAT have shown some evidence of being able to predict the pass-rate of the NCLEX-RN. ${ }^{[8]}$ The TEAS has demonstrated that it is able to predict first semester success among nursing studies. ${ }^{[22]}$

Emotional intelligence tests have been used to assess personcentred skills or personal qualities, such as self-awareness and social interaction, in the on-site selection of nursing students. ${ }^{[3,24]}$ Rankin $^{[3]}$ used the Assessing Emotions Scale (AES) to assess the emotional intelligence of nursing student applicants $(n=307)$ at one UK University. A significant predictive relationship was found between emotional intelligence and three program outcomes, practice performance, academic performance and retention, even after controlling for prior academic achievement, age and gender. Prior academic attainment and overall emotional intelligence did not correlate, indicating that the two predict different outcomes. ${ }^{[3]}$ Stenhouse et al., ${ }^{[24]}$ used the Trait Emotional Intelligence Questionnaire-Short Form and the Schutte's Emotional Intelligence Scale upon entry to adult, mental health and midwifery programs $(n=598)$. They found that emotional intelligence scores were not associated with performance, but social connection scores for students withdrawing and remaining were statistically significantly different.

In conclusion, there is a scarce amount of evidence of the predictive value of nursing student selection methods, specifically to assess non-cognitive skills of the applicants.

\section{MeTHODS}

\subsection{Aim}

The aim of this study is to compare the predictive value of two on-site selection methods used in nursing student selection, namely, psychological aptitude test and literaturebased exam. The ultimate goal of the study is to provide evidence-based suggestions for nurse educators on future on-site selection methods. Three research questions were posed:

(1) What is the difference in the levels of knowledge and skills of the two cohorts of nursing students at two measurement points?
(2) What is the difference in the study success of nursing students between the two cohorts at two measurement points?

(3) What factors predict the differences in the levels of knowledge and skills, and study success of nursing students between the two cohorts at two measurement points?

\subsection{Design}

The study design was a cohort study that utilised admission archives, study records and a self-report questionnaire.

\subsection{Participants}

All students selected for nursing programs $(\mathrm{N}=626$, namely; nursing, midwifery, public health nursing) at a university of applied sciences (UAS) in Southern Finland between autumn 2002 and autumn 2004 were considered eligible to participate in the study. Students selected for admission to the programs based on a psychological aptitude test (including teacher interviews) (3 intakes; autumn 2002, spring 2003, autumn 2003) were allocated to Cohort I. Students selected using a literature-based exam (2 intakes; spring 2004, autumn 2004) were allocated to Cohort II.

At the time of the study, approximately 120 nursing, 70 midwifery and 40 public health nursing students were accepted into the programs each year at the UAS in question. A psychological aptitude test with teacher interviews had been the dominating on-site selection method, and was carried out for the last time in autumn 2003. The UAS changed the on-site selection method to a literature-based exam in 2004 to evaluate theoretical abilities and motivation of the applicants more cost-effectively. As part of the revision, the psychological aptitude test was omitted.

\subsection{The psychological aptitude test and literature-based exam}

The psychological aptitude test undertaken by Cohort I (years 2002, 2003) comprised six parts: learning abilities, study strategies, personality testing (Wartegg I \& II, Sentence Completion Test, SELF-test), group situation, one-on-one interview with a psychologist and one-on-one interview with a nursing teacher. The maximum score given was 55 points. In preparation for the literature-based entrance exam, applicants needed to read a nursing ethics book, which included themes such as fundamentals of nursing ethics, theory of ethics, ethical decision-making, ethical challenges in nursing, ethical principles regarding patients and nursing, ethics in various clinical contexts, ethical guidelines, and ethics from a societal perspective. The literature-based exam, undertaken by Cohort II, was developed and piloted in 2003. The final version of the exam comprised 130 statements, and applicants 
indicated whether the statements were correct or incorrect, or if they did not know the answer. Applicants were awarded 0.5 points for each correct answer, -0.5 points for each incorrect answer, and "don't know" responses yielded 0 points. The statements handled topics such as ethical decision-making, ethics in general and ethics in research. The maximum score was 65 points.

\subsection{Procedure}

Nursing students were asked to complete the self-report questionnaire during their tutorial classes in their third semester (Time 1) and during their final semester (Time 2). The third semester was chosen as the first measurement point because the majority of the attrition in the nursing programs takes place during the first year of nursing education. The longitudinal data was collected between May 2004 and May 2009 (see Figure 1).

\subsection{Data collection}

The multimethod data collection process included the use of admission archives, study records and a structured selfreport questionnaire. It was also considered important to control covariates (e.g., age, previous work experience and nursing program). The entrance examination overall exam scores were collected from the admission archives of the UAS. Study success was measured using study records to establish grade point averages (GPAs) and study progress. GPAs were calculated from pre-determined courses (see Table 1). Study progress was established using the data on the number of students that had stayed in the program (retention) and the number of students that had resigned from the program (attrition).

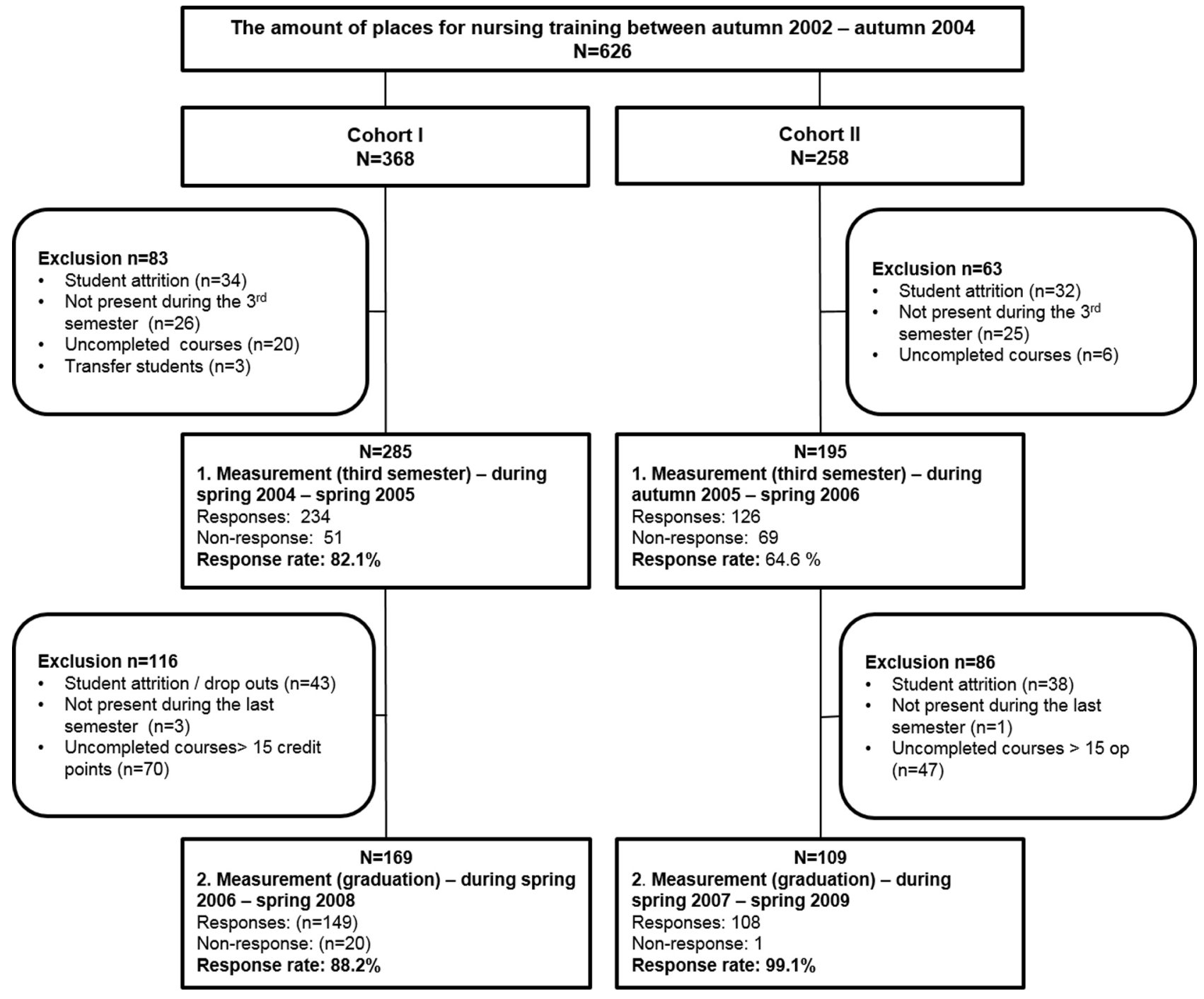

Figure 1. Response rates, exclusions and measurement points (Cohort I = students selected with psychological test, Cohort II = students selected with literature-based exam) 
Table 1. Data from the study records

\begin{tabular}{|c|c|c|}
\hline & Measurement I & Measurement II \\
\hline \multicolumn{3}{|l|}{ Study progress } \\
\hline Clinical practice & Number of completed clinical practice credit points & \\
\hline Overall study progress & Number of credit points & Number of credit points \\
\hline \multicolumn{3}{|c|}{ GPA of pre-determined courses } \\
\hline Nursing-related subjects & $\begin{array}{l}\text { 1. Basics of nursing } \\
\text { 2. Rehabilitative and supportive nursing }\end{array}$ & $\begin{array}{l}\text { 1. Basics of nursing } \\
\text { 2. Rehabilitative and supportive nursing } \\
\text { 3. Acutely ill nursing } \\
\text { 4. Mental health and substance abuse nursing } \\
\text { 5. Nursing of children and adolescents } \\
\text { 6. Nursing of the elderly } \\
\text { 7. Adult health promotion and nursing }\end{array}$ \\
\hline $\begin{array}{l}\text { Research and science- } \\
\text { related subjects }\end{array}$ & $\begin{array}{l}\text { 1. Introduction to philosophy and research } \\
\text { 2. Fundamentals of research I } \\
\text { 3. Fundamentals of nursing science }\end{array}$ & $\begin{array}{l}\text { 1. Introduction to philosophy and research } \\
\text { 2. Fundamentals of research I } \\
\text { 3. Fundamentals of nursing science } \\
\text { 4. Final thesis and publication }\end{array}$ \\
\hline
\end{tabular}

Note. Measurement I = third semester; Measurement II = graduation.

The levels of knowledge and skills was measured using the Student Nurses' Knowledge and Skills (SNKS) questionnaire developed by Eriksson, Hupli \& Leino-Kilpi for this study. While the SNKS questionnaire was being developed, a previously developed questionnaire by Solante ${ }^{[25]}$ was utilised. The instrument by Solante was modified and further developed with the written permission of the author. Only one of the subscales (interaction with patients) was used as per the original instrument. All other subscales were modified, and two new subscales were added. The SNKS questionnaire comprises 138 items and seven subscales: theoretical knowledge (medical and nursing related) (53 items), patient education ( 9 items), professional interaction (16 items), clinical skills (35 items), decision-making skills ( 9 items), teamwork skills ( 8 items) and research and development skills (8 items). Each item was rated with a four-point Likert scale, with answers ranging from strongly disagree to strongly agree. Higher scores indicated higher levels of knowledge and skills of nursing students. The questionnaire took approximately 20 minutes to complete. The SNKS questionnaire was tested and found reliable using Cronbach's alfa at the first and second measurement points, the reliability ranging in the seven main subscales from 0.82 to 0.93 and 0.85 to 0.94 , consecutively.

\subsection{Sample}

All in all, 413 undergraduate nursing students participated in the study (see Figure 1). Prospective data were collected during the third semester and at the time of graduation. The response rates were considered to be high at both measurement points (see Figure 1). Out of the 413 participants, 201 participated in both measurement points (follow-up rate of 49\%). Retrospective data included entrance examination results for Cohort I and Cohort II students. The entrance examination results for 14 students were not available. Stu- dents who had completed the pre-determined courses (see Table 1) and had enrolled for their third or their last semester were included in the study. Students who had dropped out of the program (resigned), were absent during their third or last semester, had transferred from a different UAS or had not completed the pre-determined courses were excluded from the study (see Figure 1).

\subsection{Ethical considerations}

Responsible ethical conduct was followed throughout each phase of this study. ${ }^{[26]}$ Approval for this research was granted by the institution's research committee. The data were obtained through self-reported data, and the institution's entry exam archives and study records. During face-to-face recruitment, students were informed of the study, and were assured that participation was voluntary and would not affect their grades or progress in the program. The recruitment and data collection took place during tutorial lectures by a member of the research team. Thus, the data collection did not involve teachers who were responsible for teaching the groups. The cohort design required the identification of the students. The names and university identification numbers were coded to maintain anonymity of the nursing students. The original questionnaires were destroyed after the data analysis and reporting of the results.

\subsection{Data analysis}

Data were analysed using SPSS software, version 18.0, and SAS, version 9.1. Descriptive statistics were used to describe the sample characteristics. Seven categories were formed according to the subscales of the SNKS questionnaire to compare the self-reported levels of knowledge and skills between the two cohorts. An overall score of the level of knowledge and skills was calculated as an average of the mean values of the seven subscales. Study success was established through the study progress (clinical practice credit 
points, overall credit points), and the GPAs of pre-determined courses (nursing-related, research and science-related studies) (see Table 1). Differences in the levels of knowledge and skills, and study success between the two cohorts were examined using an unpaired $T$-test and a Wilcoxon test (when appropriate). The relationships of sample characteristics to knowledge and skills, and study success were examined with an unpaired $T$-test and a one-way ANOVA with post hoc tests (Tukey) to avoid type I errors. ${ }^{[27]}$ The relationship of the self-reported data and study success was examined with Pearson's correlation coefficient. Linear regression was used to control the effect of covariates regarding the significant differences within the two cohorts. The selection method and the sample characteristics that were significantly related to the level of knowledge and skills, and study success were selected for the linear regression analysis. The analysis was performed stepwise, and continued until all of the included variables increased the model prediction significantly. The statistical test was considered to be significant if the $p$-value was $<.05 .^{[27]}$

\section{RESULT}

\subsection{Participants}

The sample characteristics of the nursing students of the two cohorts were examined (see Table 2). At the first measurement point (third semester), there were significant differences between the cohorts in age, marital status and previous work experience.

Table 2. Sample characteristics of the cohort study

\begin{tabular}{|c|c|c|c|c|c|c|c|c|c|c|}
\hline \multirow{3}{*}{ Characteristics } & \multicolumn{4}{|c|}{ Measurement I } & \multirow{3}{*}{$p$-value } & \multicolumn{4}{|c|}{ Measurement II } & \multirow{3}{*}{$p$-value } \\
\hline & \multicolumn{2}{|c|}{ Cohort I $(n=234)$} & \multicolumn{2}{|c|}{ Cohort II (n = 126) } & & \multicolumn{2}{|c|}{ Cohort I (n = 149) } & \multicolumn{2}{|c|}{ Cohort II (n = 108) } & \\
\hline & $\mathbf{n}$ & $\%$ & $\mathbf{n}$ & $\%$ & & $\mathbf{n}$ & $\%$ & $\mathbf{n}$ & $\%$ & \\
\hline \multicolumn{11}{|l|}{ Gender } \\
\hline Female & 218 & 93.2 & 123 & 97.6 & \multirow[t]{2}{*}{ NS } & 145 & 97.3 & 104 & 96.3 & \multirow[t]{2}{*}{ NS } \\
\hline Male & 16 & 6.8 & 3 & 2.4 & & 4 & 2.7 & 4 & 3.7 & \\
\hline \multicolumn{11}{|l|}{ Marital status } \\
\hline Not married & 113 & 49.8 & 45 & 36.6 & \multirow[t]{2}{*}{$.0179^{*}$} & 89 & 60.1 & 67 & 64.4 & \multirow[t]{2}{*}{ NS } \\
\hline Married/co-habiting & 114 & 50.2 & 78 & 63.4 & & 59 & 39.9 & 37 & 35.6 & \\
\hline \multicolumn{11}{|c|}{ Number of under aged children } \\
\hline Yes & 29 & 12.4 & 13 & 10.3 & \multirow[t]{2}{*}{ NS } & 21 & 14.1 & 14 & 13.0 & \multirow[t]{2}{*}{ NS } \\
\hline No & 205 & 87.6 & 113 & 89.7 & & 128 & 85.9 & 94 & 87.0 & \\
\hline \multicolumn{10}{|l|}{ Nursing program } & \multirow{5}{*}{ NS } \\
\hline Nursing & 125 & 53.4 & 57 & 45.6 & \multirow{4}{*}{ NS } & 70 & 46.9 & 58 & 55.2 & \\
\hline Public health nursing & 38 & 16.2 & 25 & 20.0 & & 31 & 20.8 & 24 & 22.9 & \\
\hline Midwifery & 71 & 30.3 & 43 & 34.4 & & 48 & 32.2 & 23 & 21.9 & \\
\hline Other reason & 6 & 2.6 & 2 & 1.6 & & 5 & 3.4 & 3 & 2.8 & \\
\hline \multicolumn{11}{|c|}{ The level of basic education } \\
\hline Elementary school & 37 & 16 & 11 & 9 & \multirow{3}{*}{ NS } & 23 & 15 & 10 & 9 & \multirow{3}{*}{ NS } \\
\hline High school & 8 & 3 & 5 & 4 & & 3 & 2 & 4 & 4 & \\
\hline Matriculation exam & 188 & 81 & 110 & 87 & & 123 & 83 & 94 & 87 & \\
\hline \multicolumn{11}{|c|}{ Previous professional education } \\
\hline Yes & 84 & 36 & 35 & 28 & NS & 56 & 38 & 30 & 28 & NS \\
\hline No & 146 & 64 & 91 & 72 & & 93 & 62 & 76 & 72 & \\
\hline Working while studyin & & & & & & & & & & \\
\hline Yes & 88 & 38 & 56 & 45 & NS & 96 & 64 & 72 & 69 & NS \\
\hline No & 145 & 62 & 69 & 55 & & 53 & 36 & 33 & 31 & \\
\hline Working outside of nu & ile stu & & & & & & & & & \\
\hline Yes & 60 & 26 & 28 & 22 & NS & 22 & 15 & 14 & 13 & NS \\
\hline No & 172 & 74 & 97 & 78 & & 127 & 85 & 91 & 87 & \\
\hline Previous work experie & Irsing & & & & & & & & & \\
\hline Yes & 90 & 39 & 30 & 24 & $.0038^{*}$ & 54 & 36 & 27 & 25 & NS \\
\hline No & 141 & 61 & 96 & 76 & & 95 & 64 & 79 & 75 & \\
\hline Consideration of drop & & & & & & & & & & \\
\hline Often/quite often & 13 & 6 & 8 & 6 & & 9 & 6 & 9 & 9 & NS \\
\hline Sometimes & 87 & 38 & 42 & 34 & NS & 63 & 42 & 45 & 44 & NS \\
\hline Never & 127 & 56 & 75 & 60 & & 77 & 52 & 48 & 47 & \\
\hline
\end{tabular}


As shown in Table 2, significant differences in sample characteristics were not detected between the cohorts at the second measurement point (graduation) (see Table 2).

\subsection{Differences in the levels of knowledge and skills of nursing students between the two cohorts}

In the third semester (Time 1), significant differences were detected in two subscales (out of seven): theoretical knowledge and clinical skills (Table 3). Students selected using the psychological aptitude test (Cohort I) assessed their level of theoretical knowledge higher (mean 2.22, SD 0.29) than students selected using the literature-based exam (Cohort II) assessed theirs (mean 2.16, SD 0.32) $(p=.04)$. Cohort I students also assessed their level of clinical skills higher (mean 2.84, SD 0.38) than Cohort II students did (mean 2.72, SD 0.41) $(p=.01)$. At the time of graduation (Time 2$)$, differences between the two cohorts were detected in one of the subscales (out of seven), that being clinical skills (see Table 3). Cohort I students assessed their level of clinical skills (mean 3.24, SD 0.38) higher than Cohort II students assessed theirs (mean 3.10, SD 0.44) $(p$-value $=.006)$.

Table 3. Self-reported levels of knowledge and skills of the two cohorts at the two measurement points

\begin{tabular}{|c|c|c|c|c|c|c|c|c|c|c|c|c|c|c|}
\hline & \multicolumn{6}{|c|}{ Measurement I } & \multirow{3}{*}{$p$} & \multicolumn{6}{|c|}{ Measurement II } & \multirow{3}{*}{$p$} \\
\hline & \multicolumn{3}{|c|}{ Cohort I $(n=234)$} & \multicolumn{3}{|c|}{ Cohort II $(n=118)$} & & \multicolumn{3}{|c|}{ Cohort I $(n=141)$} & \multicolumn{3}{|c|}{ Cohort II $(n=101)$} & \\
\hline & Mean & SD & Range & Mean & SD & Range & & Mean & SD & Range & Mean & SD & Range & \\
\hline Overall score & 2.52 & 0.31 & $1.64-3.40$ & 2.46 & 0.33 & $1.57-3.83$ & NS & 2.97 & 0.32 & $2.16-3.73$ & 2.93 & 0.37 & $1.59-3.66$ & NS \\
\hline Theoretical knowledge ${ }^{*}$ & 2.22 & 0.29 & $1.60-3.10$ & 2.16 & 0.32 & $1.40-3.90$ & $.04^{\ddagger}$ & 2.73 & 0.35 & $1.75-3.68$ & 2.77 & 0.45 & $1.42-3.79$ & NS \\
\hline Patient education ${ }^{*}$ & 2.27 & 0.52 & $1.00-3.56$ & 2.21 & 0.49 & $1.33-4.00$ & NS & 2.89 & 0.47 & $2.00-4.00$ & 2.81 & 0.51 & 1.33-3.89 & NS \\
\hline Professional interaction $^{*}$ & 2.78 & 0.43 & $1.63-3.81$ & 2.77 & 0.46 & $1.44-4.00$ & NS & 3.05 & 0.39 & $1.81-4.00$ & 3.03 & 0.47 & $1.25-3.94$ & NS \\
\hline Clinical skills ${ }^{*}$ & 2.84 & 0.38 & $1.86-3.77$ & 2.72 & 0.41 & $1.60-3.69$ & $.01^{\dagger}$ & 3.24 & 0.38 & $2.17-4.00$ & 3.10 & 0.44 & $1.83-3.83$ & .006 \\
\hline Decision-making skills ${ }^{*}$ & 2.68 & 0.50 & $1.00-4.00$ & 2.65 & 0.45 & $1.33-3.89$ & NS & 3.20 & 0.48 & $2.00-4.00$ & 3.09 & 0.46 & $2.00-4.00$ & NS \\
\hline Teamwork skills" & 2.98 & 0.47 & $1.63-4.00$ & 2.92 & 0.48 & $1.38-4.00$ & NS & 3.23 & 0.46 & $2.25-4.00$ & 3.16 & 0.44 & $1.63-4.00$ & NS \\
\hline $\begin{array}{l}\text { Research and development } \\
\text { skills }^{*}\end{array}$ & 2.28 & 0.46 & $1.13-3.63$ & 2.27 & 0.45 & $1.25-3.63$ & NS & 2.84 & 0.48 & $1.75-4.00$ & 2.77 & 0.46 & $1.75-4.00$ & NS \\
\hline
\end{tabular}

\subsection{Differences in the study success of nursing students between the two cohorts}

During the third semester (Time 1), there were no significant differences between the cohorts in study progress (see Table 4). However, significant differences were detected in the GPAs of the nursing students. Cohort II students succeeded better in nursing-related studies, as well as in the research and science-related studies, than Cohort I students. At the time of graduation (Time 2), there were no significant differences in study progress or in the GPAs between the two cohorts.

Table 4. Study success of the two cohorts at the two measurement points

\begin{tabular}{|c|c|c|c|c|c|c|c|c|c|c|c|c|c|c|}
\hline & \multicolumn{7}{|c|}{ Measurement I } & \multicolumn{7}{|c|}{ Measurement II } \\
\hline & \multicolumn{3}{|c|}{ Cohort I $(n=234)$} & \multicolumn{3}{|c|}{ Cohort II (n = 126) } & \multirow{2}{*}{$p$} & \multicolumn{3}{|c|}{ Cohort I $(n=149)$} & \multicolumn{3}{|c|}{ Cohort II $(n=108)$} & \multirow{2}{*}{$p$} \\
\hline & Mean & SD & Range & Mean & SD & Range & & Mean & SD & Range & Mean & SD & Range & \\
\hline \multicolumn{15}{|l|}{ Study progress } \\
\hline Amount of clinical practice credits & 24 & 5 & $8-41$ & 24 & 3 & $9-33$ & NS & 91 & 20 & $59-120$ & 87 & 18 & $66-120$ & NS \\
\hline Overall amount of credits & 80 & 9 & 39-99 & 79 & 9 & $46-93$ & NS & 236 & 27 & $203-272$ & 229 & 25 & $190-273$ & NS \\
\hline \multicolumn{15}{|l|}{ GPA } \\
\hline Nursing related courses ${ }^{*}$ & 3.1 & 0.6 & $1.5-5$ & 3.3 & 0.7 & $2-5$ & $.0033^{\dagger}$ & 3.5 & 0.5 & $2.3-4.9$ & 3.6 & 0.5 & $2.4-4.7$ & NS \\
\hline Research and science related courses ${ }^{*}$ & 2.8 & 0.9 & $1-5$ & 3.1 & 0.9 & $1-5$ & $.0011^{\dagger}$ & 3.2 & 0.7 & $1.7-5.0$ & 3.3 & 0.8 & $1.8-5.0$ & NS \\
\hline
\end{tabular}

3.4 Predictors of the level of knowledge and skills, and study success of nursing students between the two cohorts

According to the linear regression analysis, two factors, the student selection method and the nursing program, most often account for the detected statistical differences between the cohorts in the levels of knowledge and skills, and study success (see Table 5). However, the overall variance remains below $11 \%$, indicating that neither of the two on-site selection methods were particularly predictive of the nursing students' levels of knowledge and skills or study success. 
Table 5. Predictors of the levels of knowledge and skills and GPAs of nursing students using linear regression

\begin{tabular}{|c|c|c|c|c|}
\hline \multirow{4}{*}{ Predictor variables } & \multirow{2}{*}{\multicolumn{2}{|c|}{$\begin{array}{l}\text { Self-reported level of knowledge and skills } \\
\text { Clinical skills }\end{array}$}} & \multicolumn{2}{|c|}{ GPA of pre-determined courses } \\
\hline & & & Nursing-related subjects & Research and science-related subjects \\
\hline & Measurement point $\mathrm{I}^{\dagger}$ & Measurement point II $^{\dagger}$ & Measurement point $I^{\ddagger}$ & Measurement point $I^{\ddagger}$ \\
\hline & $p$-value & $p$-value & $p$-value & $p$-value \\
\hline Selection method & .0305 & .0130 & .0009 & .0080 \\
\hline Age & - & - & .0012 & - \\
\hline Nursing program & - & .0396 & - & .0011 \\
\hline Level of basic education & - & - & - & .0006 \\
\hline Previous work experience in nursing & .0038 & - & - & - \\
\hline Model prediction & $4.4 \%$ & $5.7 \%$ & $5.4 \%$ & $10.3 \%$ \\
\hline
\end{tabular}

\section{DiscuSSION}

\subsection{Main results}

Based on previous literature, it has been unclear which onsite selection methods should be used to best predict the study success of nursing students. ${ }^{[12,13]}$ Therefore, this study aims to compare the predictive value of two on-site selection methods on study success of undergraduate nursing students. Firstly, the results of this study demonstrate that there was very little difference in the self-reported levels of knowledge and skills, or the objectively assessed study success of nursing students between the two cohorts. This result is somewhat surprising because we initially assumed that students selected with the psychological aptitude test would demonstrate higher levels of knowledge and skills, and better study success than students selected with a literature-based exam. This initial assumption was based on the long history of psychological aptitude tests in Finland, and the inclusion of cognitive and non-cognitive elements. Because of the lack of previously reported studies on the use of psychological aptitude tests in nursing student selection, the results of this study cannot be directly compared to previous study results.

Secondly, the results of this study suggest that both psychological aptitude tests and the literature-based exams can be used to predict nursing performance and study success to some extent. However, the results of the linear regression analysis demonstrate that the selection method only explains a small proportion of the variance (4.4\%-10.3\%) (see Table 5). It is recognised that the explanatory power of the two on-site selection methods might have been higher if all of the applicants would have been invited to take the entrance exam, which would have created a more heterogeneous group. However, during the selection process of this study, approximately one-third of the applicants were invited to take the entrance exam based on their previous academic achievement. The group was, therefore, more homogenous, which may have decreased the explanatory power of the two methods.
Thirdly, based on the study results, it is impossible to conclude whether future on-site selection methods should concentrate more on the assessment of cognitive or non-cognitive skills. It would have been interesting to assess the predictive validity of the different parts of the psychological aptitude test, such as personality testing (Wartegg I \& II, Sentence Completion Test, SELF-test) and learning abilities, but unfortunately, we were only able to access the overall scores of the psychological aptitude test. According to the previous related literature, a combination of both cognitive ${ }^{[7,9]}$ and non-cognitive ${ }^{[3,7,24]}$ approaches may be useful in future nursing student selection. However, further identification of factors and methods to assess cognitive and non-cognitive skills of nursing students is required.

Fourthly, even though the results demonstrate very little difference between the two selection methods, the methods vary greatly in cost. This cost difference is notable for Finnish nursing programs because the institutions are obligated to cover the entire cost of entrance examinations. The applicants are entitled to participate in entrance examinations free of charge. ${ }^{[28]}$ To date, there is only one publication regarding the costs of entrance examinations in the social and healthcare education in Finland. According to Djupsjöbacka, ${ }^{[17]}$ in 2002-2003, it was estimated that the total cost of a psychological aptitude test (including interviews organised by teaching staff) was 82.62 euros per applicant, whereas the total cost of a selection method including a book exam, interviews organised by teaching staff and a group discussion was 44.40 euros per applicant. The estimation of these costs includes the planning, implementation and evaluation of the examination. ${ }^{[17]}$ Currently, on-site selection methods vary greatly in Finnish nursing programs. According to a survey conducted in January 2014 (answers from 13 out of 23 universities of applied sciences), eight of the universities of applied sciences were using psychological aptitude tests combined with either an individual interview with a psychol- 
ogist or a combination of an individual interview and a group interview/situation. One UAS was using a literature-based exam, and four were using literature-based exams combined with individual/group interviews or both. At nine of the universities of applied sciences, mathematical skills were being tested alongside other on-site selection methods, and at three, language skills were being assessed. ${ }^{[6]}$ However, there is no further research data of the predictive value of these selection methods.

\subsection{Limitations}

In this cohort study, the most common sources of bias (information, selection and confounding bias) were evaluated regarding the interpretation of the results. Information bias refers to accurate and consistent measurements and selection bias to representativeness of the target population. ${ }^{[29,30]}$ In this study, the SNKS questionnaire was found to be a reliable instrument with an internal consistency ranging from 0.82 to 0.94 at the two measurement points. ${ }^{[31]}$ Selection bias was reduced by selecting all nursing applicants who were admitted to the UAS during the indicated time period of this study. Response rates of this study were considered high (see Figure 1), which also reduced selection bias. It was calculated that the study sample represented approximately $6.5 \%$ of all Finnish nursing students at the time of the study. The age and gender of the study sample followed the average age and gender of Finnish nursing students in general. Thus, the study sample can be considered representative of the Finnish nursing student population. The study was applied at one nursing school to minimise the differences in the curriculum and study environment, but organising the study at one institution may have somewhat limited the study results. Confounding variables (e.g., age and nursing program) were controlled by using linear regression. ${ }^{[30]}$ It was concluded that the factors, selection method and nursing program, most often accounted for any differences. As a limitation to this study, $51 \%$ of the participants were lost in the follow-up. It is common in prospective cohort studies that all the participants cannot be followed for the entire length of the study. ${ }^{[30]}$ However, these losses may affect the validity of the results. Furthermore, the follow-up data was collected between 2004 and 2009, which may affect the way the results can be generalised today. Even though psychological aptitude tests and literature-based exams are currently used in Finland, the methods may have developed over the intervening years. This needs to be considered when interpreting the results. However, in our opinion, the time of the data collection does not affect the main results of this study. Additionally, at the time of the study, the nursing curriculum followed the
European core nursing competencies, thus increasing the likelihood of generalisability of the research results, at least in the European context.

\section{Conclusions}

The findings suggest that the two on-site selection methods are predictive of nursing students' levels of knowledge and skills (psychological test), and study success (literaturebased exam) at the beginning of their studies. However, the findings also suggest that other factors or on-site selection methods should be included to achieve better predictability. It can be concluded that further longitudinal research is needed to investigate the predictive value of the various on-site selection methods used in student selection in nursing education. Future research should include a wider scope of outcome measures to better acknowledge the demands of the nursing profession, for example, by including measures of social, emotional and clinical competence. Furthermore, objective ways to evaluate knowledge and skills or competence should be sought after. Future research should also focus on the admission/selection costs to universities. We propose that economic impact should be investigated more systematically, collecting at least the minimum set of data presented below.

- Costs

- Planning of entrance exam (e.g., content of the exam, room reservations, photocopying)

- Implementation of entrance exam (lecturers, other staff)

- Marking of entrance exam

- Feedback for the applicants

- Expert fees (e.g., psychologists, expertise in a specific method)

- Other fees (e.g., materials, venue)

- Additional information to calculate the costs

- The number of applicants who participated in the entrance exam

- The number of students selected for the program

- Cost per selected student

- Cost per applicant who participated in the exam

\section{ACKNOWLEDGEMENTS}

We would wish to thank Leigh Ann Lindholm for the language checking of this article.

\section{CONFLiCTS OF INTEREST Disclosure}

The authors declare that there is no conflict of interest. 


\section{REFERENCES}

[1] World Health Organization, WHO. Nursing \& midwifery human resources for health. Global standards for the initial education of professional nurses and midwives. 2009 [cited 2015 October 1]. Geneva. Available from: http://www. who.int/hrh/resources/standa rds/en/

[2] World Health Organization, WHO. Global Health Observatory (GHO) data. Density of nursing and midwifery personnel (total number per 1000 population, latest available year). 2017. Available from: http://www.who.int/gho/health_workforce/n ursing_midwifery_density/en/

[3] Rankin B. Emotional intelligence: enhancing value-based practice and compassionate care in nursing. Journal of Advanced Nursing. 2013; 69: 2717-2725.

[4] Flinkman M, Salanterä S. Early career experiences and perceptions - a qualitative exploration of the turnover of young registered nurses and intention to leave the nursing profession in Finland. Journal of Nursing Management. 2014; 23(8): 1050-7. https : //doi.org/10.1111/jonm. 12251

[5] Francis R. Report of the Mid Staffordshire NHS Foundation Trust Policy Inquiry. The Stationary Office, London; 2013.

[6] Talman K. Student Selection in Nursing Education. A follow-up study of two selection methods and their relations to the knowledge, skills and study motivation of nursing students [Doctoral dissertation: original text in Finnish, abstract in English]. University of Turku, Annales Universitatis Turkuensis, Series C - section 383; 2014. Available from: https://www.doria.fi/bitstream/handle/10024/96 712/AnnalesC383Talman . pdf? sequence $=2 \&$ isAllowed $=y$

[7] Gale J, Ooms A, Grant R, et al. Student nurse selection and predictability of academic success: The Multiple Mini Interview project. Nurse Education Today. 2016; 40(5): 123-127. https://doi.org/ $10.1016 / j$.nedt .2016 .01 .031

[8] Stuenkel DL. At-risk students. Do theory grades + standardized examinations $=$ success? $\quad$ Nurse Educator. 2006; 31: 207-212. https://doi.org/10.1097/00006223-200609000-00007

[9] Dante A, Valoppi G, Saiani L, et al. Factors associated with nursing students' academic success or failure: A retrospective Italian multicenter study. Nurse Education Today. 2011; 31(1): 59-64. https://doi.org/10.1016/j.nedt.2010.03.016

[10] Lancia L, Petrucci C, Giorgi F, et al. Academic success or failure in nursing students: Results of a retrospective observational study. Nurse Education Today. 2013; 33(12): 1501-1505. https : //doi.org/10.1016/j.nedt.2013.05.001

[11] Underwood L, Williams LL, Lee MB, et al. Predicting baccalaureate nursing students' first-semester outcomes: HESI admission assessment. Journal of Professional Nursing. 2013; 9: S38-S42. https://doi.org/10.1016/j.profnurs . 2012.07.003

[12] MacDuff C, Stephen A, Taylor R. Decision precision or holistic heuristic: Insights on on-site selection of student nurses and midwives. Nurse Education in Practice. 2016; 16(1): 40-46. https: //doi.org/10.1016/j.nepr.2015.06.008

[13] Pitt V, Powis D, Levett-Jones T, et al. The influence of personal qualities on performance and progression in a pre-registration nursing programme. Nurse Education Today. 2014; 34: 866-871. https: //doi.org/10.1016/j.nedt.2014.08.006

[14] Waugh A, Smith D, Horsburgh D, et al. Towards a values-based person specification for recruitment of compassionate nursing and midwifery candidates: A study of registered and student nurses' and midwives' perceptions of prerequisite attributes and key skills. Nurse Education Today. 2014; 34: 1190-1195. https ://doi .org/10.1 016/j.nedt.2013.12.009

[15] Nursing and Midwifery Council. Standards for pre-registration nursing education [Internet]. 2010 Sept [cited 2017 September 23].
Available from: https://www.nmc.org.uk/globalassets/si tedocuments/standards/nmc-standards-for-pre-regis tration-nursing-education.pdf

[16] Taylor R, Macduff C, Stephen A. A national study of selection processes for students and midwives. Nurse Education Today. 2014; 34: 1155-60. http://dx.doi .org/10.1016/j.nedt.2014.04.024

[17] Djupsjöbacka S. Selection in an examination. National Social and Health Care Student Selection Project during 2002-2003 [unofficial translation; original text in Finnish]. Diaconia University of Applied Sciences publications 2004; B: report 22. Helsinki. https: //doi.org/10.1016/j.nedt.2014.04.024

[18] Rantanen P. From selection to workforce. Examination of student selections in the vocational training and in universities of applied sciences [unofficial translation, original text in Finnish]. Publications by Ministry of Education. Ministry of Education, Finland, Helsinki 2004

[19] Ehrenfeld M, Tabak N. Value of admission interviews in selecting of undergraduate nursing students. Journal of Nursing Management. 2000; 8: 101-106. PMid:11051966 https://doi.org/10.1046/ j.1365-2834.2000.00155.x

[20] Perkins A, Burton L, Dray B, et al. Evaluation of a multiple-miniinterview protocol used as a selection tool for entry to an undergraduate nursing programme. Nurse Education Today. 2013; 33(5): 465-469, https://doi.org/10.1016/j.nedt.2012.04.023

[21] Sadler J. Effectiveness of student admission essays in identifying attrition. Nurse Education Today. 2003; 23: 620-627. https: //doi.org/10.1016/S0260-6917(03)00112-6

[22] Newton SE, Smith LH, Moore G, et al. Predicting early academic achievement in a baccalaureate nursing program. Journal of Professional Nursing. 2007; 23(3): 144-149. https://doi .org/10.101 $6 / j \cdot$ profnurs. 2006.07.001

[23] Snowden A. Emotional Intelligence and Nurse Recruitment: Rasch and confirmatory factor analysis of the trait emotional intelligence questionnaire short form. Journal of Advanced Nursing. 2015; 71(12): 2936-2949. PMid:26265433 https://doi.org/10.111 $1 / \mathrm{jan} .12746$

[24] Stenhouse R, Snowden A, Young J, et al. Do emotional intelligence and previous caring experience influence student nurse performance? A comparative analysis. Nurse Education Today. 2015; 43: 1-9. https://doi.org/10.1016/j.nedt.2016.04.015

[25] Solante S. Healthcare education outcomes. Follow-up study for graduated midwifes, nurses and public health nurses in the year 1990 [Masters dissertation; unofficial translation, original text in Finnish] University of Turku, Department of Nursing Science, Turku. 1997.

[26] Responsible conduct of research guidelines [Internet]. Finnish Advisory Board on Research Integrity; 2012 [cited 2017 April 24] Available from: http://www.tenk.fi/en/resposible-condu ct-research-guidelines

[27] Hair JF, Black WC, Babin BJ, et al. Multivariate Data Analysis. A Global Perspective. [7th ed]. Boston: Pearson; 2010.

[28] Decree on fees in the University of Applied Sciences. [Internet]. Finnish Government Decree; 2001: 2001/653 [cited 2016 Jan 16]. Available from: http://www.finlex.fi/fi/laki/alkup/2001 $/ 20010653$ ? search [type] =pika\&search [pika] $=653 \% 2 F 2001$

[29] Martin MM. Epidemiological study designs for health care research and evaluation, in A Bowling, S Ebrahim [Eds.], Handbook of health research methods. Investigation, measurement and analysis. Maidenhead: Open University Press; 2005. 98-163 p.

[30] Healy P, Devane D. Methodological considerations in cohort study designs. Nurse Researcher. 2011; 18: 32-36. https://doi.org/ 10.7748/nr2011.04.18.3.32.c8461

[31] DeVellis RF. Scale development. Theory and applications [3rd ed.] Los Angeles: Sage; 2012. 205 p. 